\title{
LA CASA RIERA DE ALELLA. UNA VIVIENDA EXPERIMENTAL DE BLOQUE DE MORTERO. ESPAÑA
}

\author{
(LA CASA RIERA DE ALELLA - AN EXPERIMENTAL MORTAR-BLOCK HOME, SPAIN)
}

\section{José Ignacio de Llorens Durán}

Alfonso Soldevila Barbosa

Drs. Arquitectos, profesores de la Escuela Técnica Superior de Arquitectura de Barcelona - España

\section{RESUMEN}

Como continuación de los trabajos realizados anteriormente se ha construido una vivienda experimental cuyas características principales son:

1. La concepción elemental del edificio y sus partes.

2. La independencia con la que se tratan los elementos constructivos: muros, cubierta, carpinteria, forjados, tabiques, instalaciones y acabados, las soluciones constructivas concretas que se adoptan y el comportamiento térmico.

3. La calidad del espacio interior.

4. La facilidad de adaptación al usuario, de mantenimiento y transformación.

5. La facilidad de adaptación al medio.

Se trata de un sistema constructivo que se confunde con el resultado arquitectónico y viceversa, ya que la mayor parte de soluciones responden a planteamientos globales del proyecto y la mayor parte de decisiones de proyecto responden a condicionantes de tipo constructivo. Es un ejemplo de arquitectura implicada en la construcción.

\section{SUMMARY}

Following previous studies, we have built an experimental home, with the following main characteristics:

1. The elemental concept of the building and its parts.

2. The independence which the building elements are dealt with: walls, roof, woodwork, wrought-iron, partition walls, installations and finishes, the specific building solutions used and thermal performance.

3. The interior space quality.

4. Facility of adaptation to the user, maintenance and transformation.

5. Facility of adaptation to the environment.

This refers to a building system which blends in with the architectonic results and vice-versa, as the mayority of the solutions respond to global project execution and the majority of the project decisions are conditioned by building specifications. It is an example of architecture involved in building.

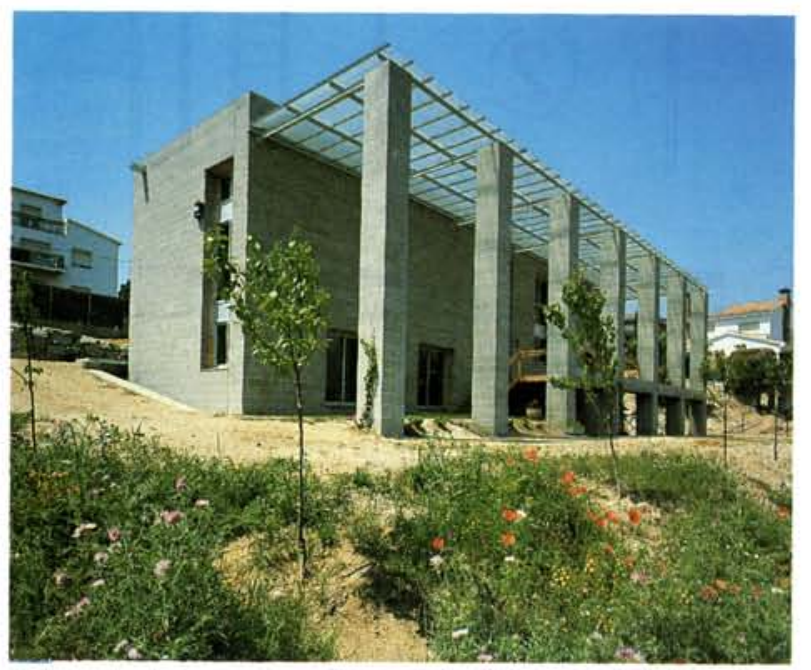

\section{DESCRIPCIÓN GENERAL DEL EDIFICIO}

El edificio se plantea como un contenedor rectangular de $5,80 \times 22,20 \times 8,40 \mathrm{~m}$ que contiene a la vivien. da desarrollada sobre cuatro plataformas a distinto nivel que incluyen (Figs. 1, 2):

- nivel 1 ( $\operatorname{cota}-1,20)$ : sala de estar;

- nivel 2 (cota $+0,00)$ : acceso, cocina, comedor, baño y dormitorio;

- nivel 3 (cota $+1,20)$ : dormitorio, baño y estudio;

- nivel 4 (cota $+2,40)$ : espacio de juego, dos dormitorios y baño. 


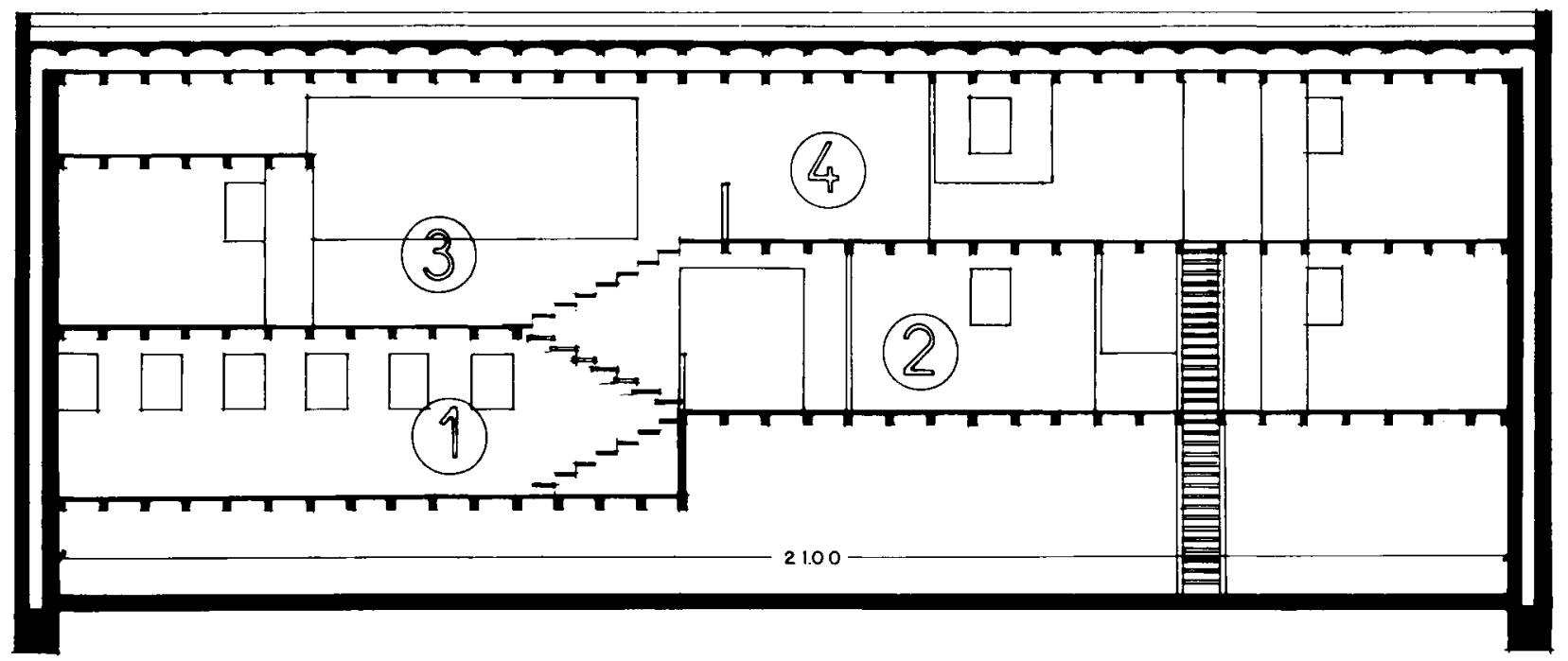

Fig. 1.-Sección longitudinal.
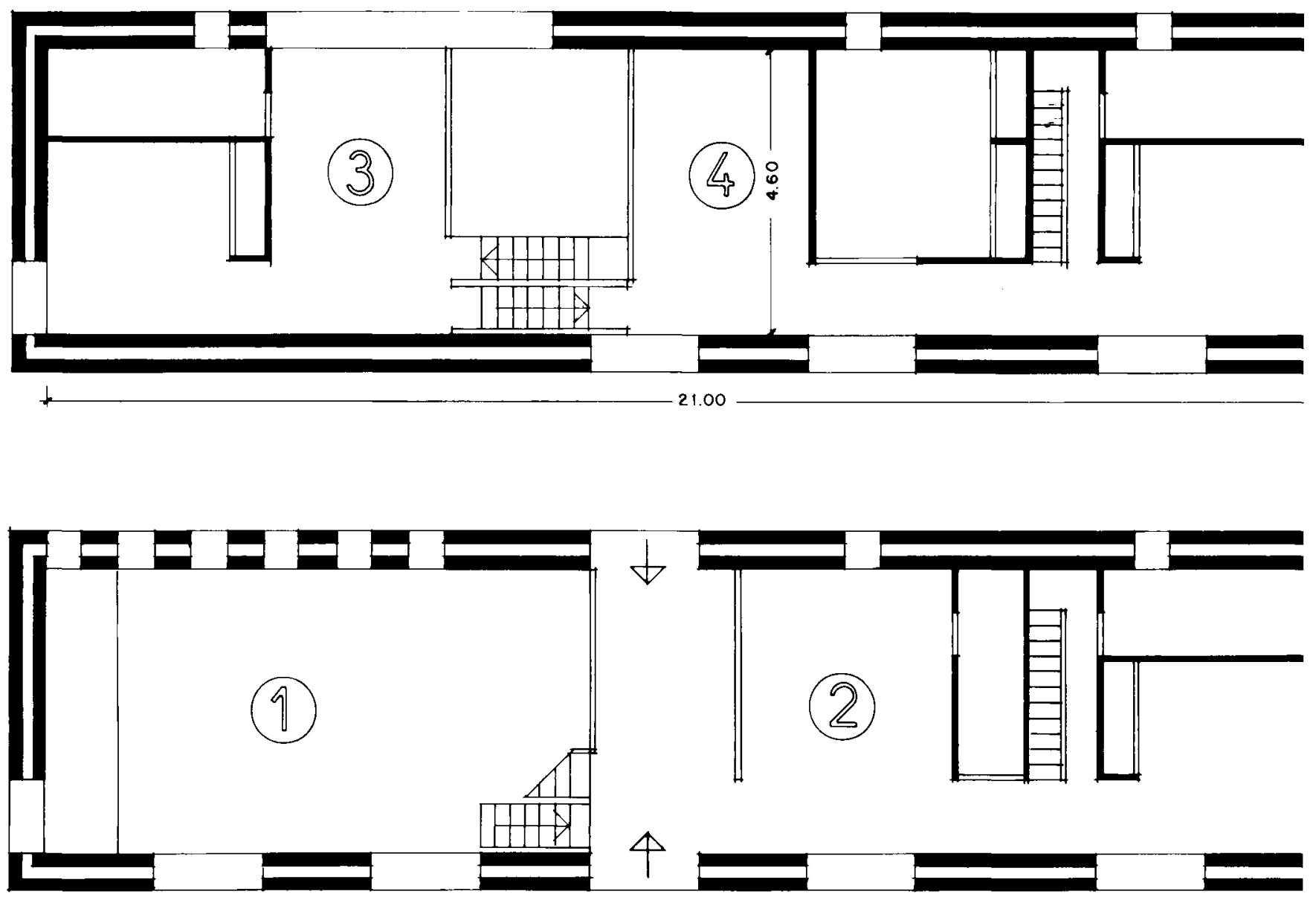

Fig. 2.-Planta niveles 1, 2, 3 y 4.

Un gran espacio central bien iluminado y ventilado conecta las cuatro plataformas entre sí. Incluye el acceso, que reduce la longitud de los recorridos posibles porque está situado en el centro de gravedad.

Los niveles inferiores (1 y 2) quedan separados del suelo

(c) Consejo Superior de Investigaciones Científicas Licencia Creative Commons 3.0 España (by-nc) por una cámara alta que puede utilizarse como sótano para almacenamiento, servicios o taller.

Es rectangular para que la dimensión transversal permita la construcción de los forjados con una sola crujía, evitando luces excesivas o compartimentaciones 


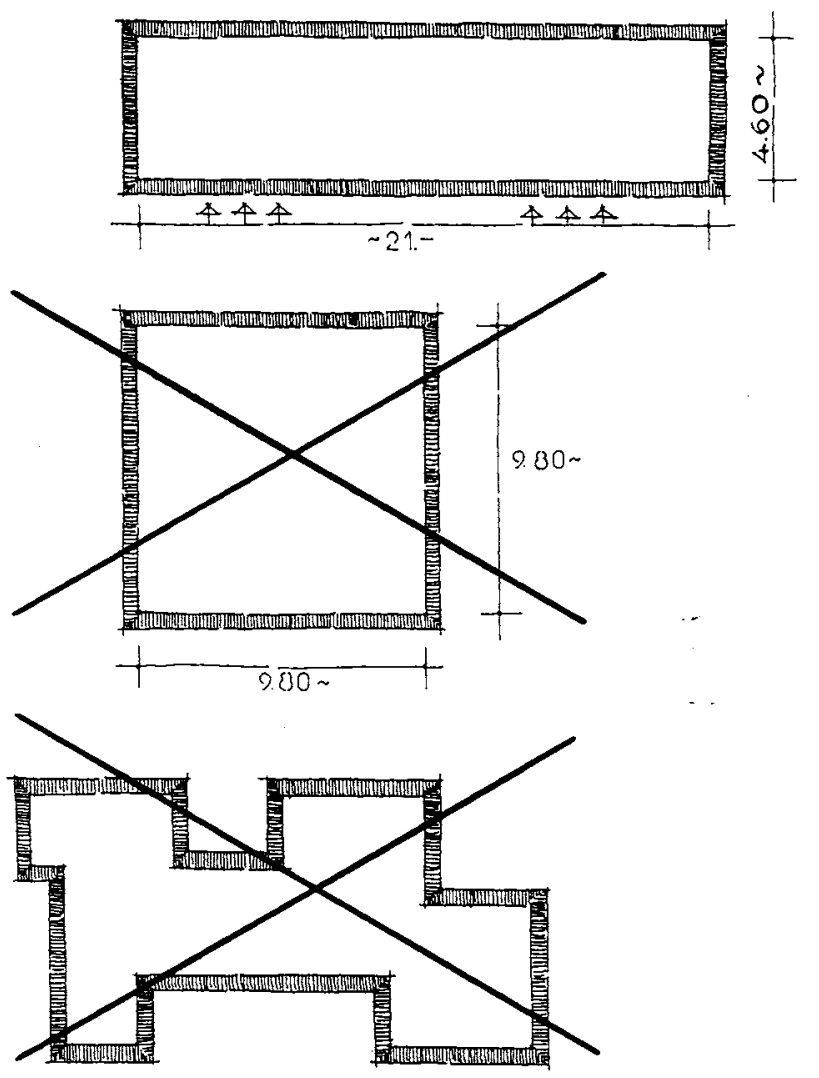

Fig. 3.-El rectángulo permite construir con crujia única. El cuadrado requiere apoyo interior. Los retranqueos incrementan la cantidad de pared.

rígidas interiores. No se retranquean las fachadas para simplificar la construcción y disminuir la superficie de la envolvente exterior (Fig. 3).

\section{CARACTERISTIICAS CONSTRUCTIVAS}

El sistema constructivo se basa en la caja exterior de muros de $60 \mathrm{~cm}$ de espesor, formados por dos hojas de bloque prensado hueco de mortero gris y una cámara ventilable que incluye el aislamiento aplacado, no vertido, sobre la cara exterior de la hoja interior.

El bloque de mortero es un elemento prefabricado a partir de materiales y procedimientos conocidos y controlables. El tamaño de la pieza es grande $(20 \times 40 \times$ $\times 20 \mathrm{~cm}$ ) por lo que se requieren menos piezas, juntas, mortero y manipulación. Es necesario modular el proyecto de manera que todas las dimensiones sean múltiplos del módulo base (medio bloque más media junta, alrededor de los $20 \mathrm{~cm}$ ). El edificio se construye con bloques enteros y medios bioques, sin necesidad de corte alguno. Las dimensiones de todos los elementos constructivos quedan regularizadas y se facilitan el replanteo y la colocación. El bloque hueco permite además macizar y armar, con lo que pueden superarse las limitaciones correspondientes a los sistemas de muros relativas a resistencia, luces, alturas y distancias entre arriostramientos.

El espesor de $60 \mathrm{~cm}$ permite que las dos hojas sean de $20 \mathrm{~cm}$ autoportantes. Para ello se macizan y arman en zunchos, jambas y esquinas y se solidarizan entre si mediante conectores galvanizados (Fig. 4).

Esta solución es el resultado de las experiencias anteriores (Llorens \& Soldevila, 1982). Se iniciaron con el muro monocapa de $20 \mathrm{~cm}$ de bloque macizo de hormigón ligero y refuerzos horizontales y verticales de bloque hueco de mortero macizado y armado. Para sustituir el bloque macizo de hormigón ligero y mejorar el aislamiento y la estanquidad, se pasó al muro de $40 \mathrm{~cm}$ de espesor total compuesto por una pared interior de $20 \mathrm{~cm}$ de bloque hueco de mortero, una cámara de aire de $12 \mathrm{~cm}$ rellena con arcilla expandida y un tabique exterior de $8 \mathrm{~cm}$ de bloque hueco de mortero gris. Esta solución presentó los inconvenientes de la permeabilidad, los puentes térmicos que aparecian en jambas, esquinas y dinteles y de la debilidad del tabique exterior. Por ello se pasó a las dos hojas independientes de $20 \mathrm{~cm}$ de espesor que resuelven los problemas de aislamiento e impermeabilidad y permiten apoyar la cubierta sobre la hoja exterior y los forjados interiores sobre la hoja interior. Además, se pueden resolver las esquinas con piezas enteras que evitan cortes e irregularidades en la modulación.

La entrega del edificio con el terreno se realiza solamente a través de los cimientos porque un patio inglés separa el muro de contención (Fig. 14). Así se evita el contacto con el suelo y se crea una galería que acoge al desagüe general. Está cubierta con malla metálica para evitar salpicaduras y acumulaciones de tierras y permitir la ventilación.

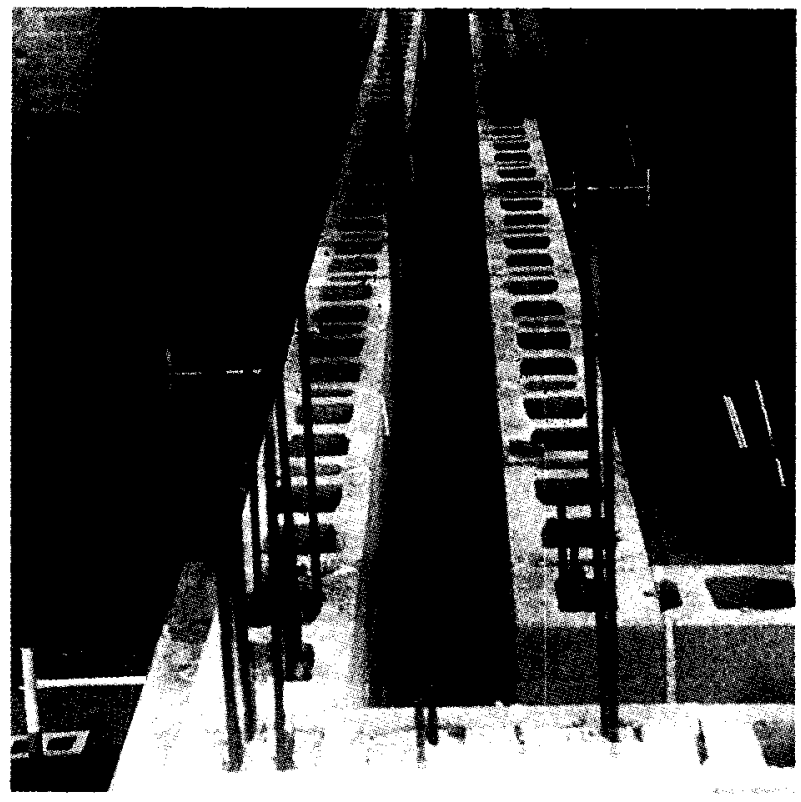

Fig. 4.-Armado de esquinas. 


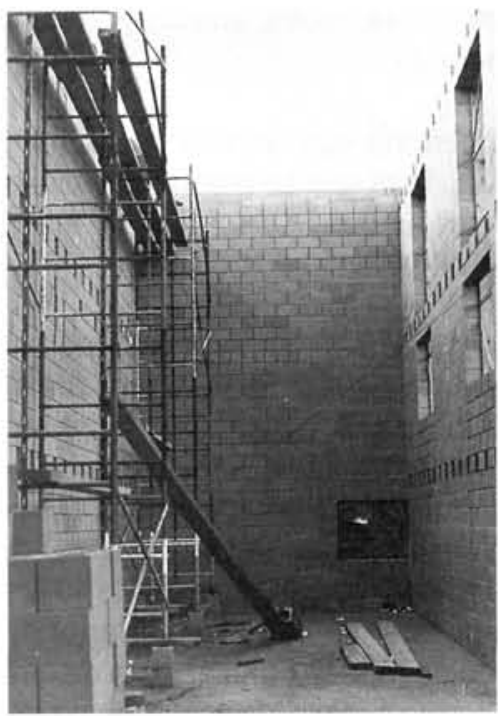

Fig. 5.- Los muros se levantan independientemente de los forjados.

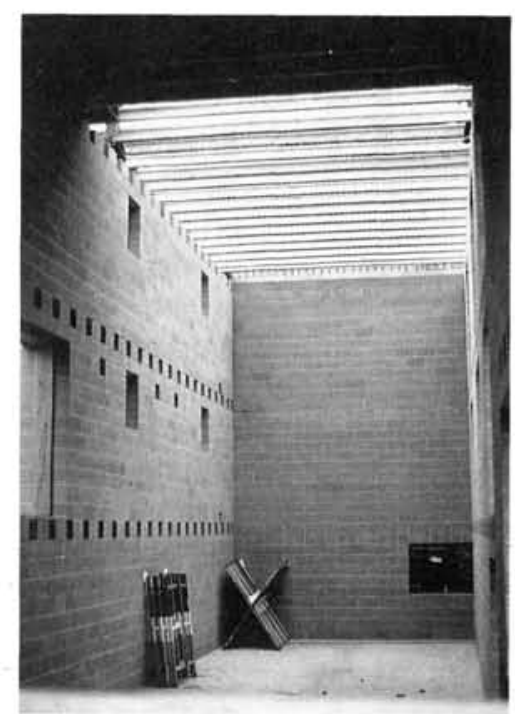

Fig. 7.-La cubierta se construye sobre los muros, antes de los forjados.

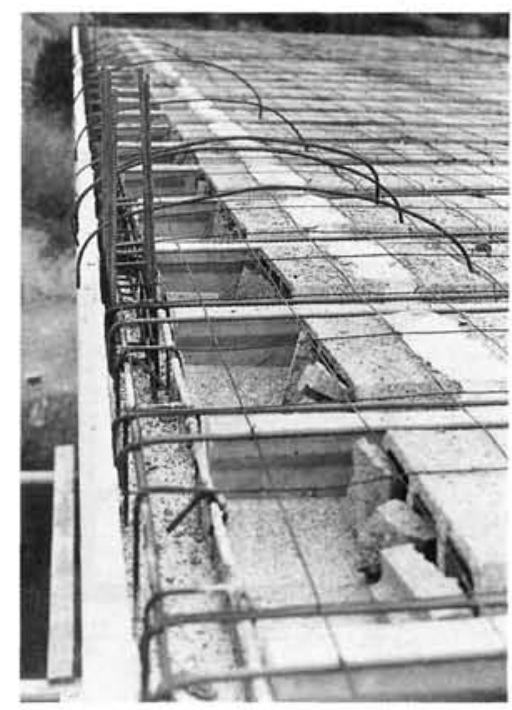

Fig. 8.-Estructura de la capa superior de la cubierta.

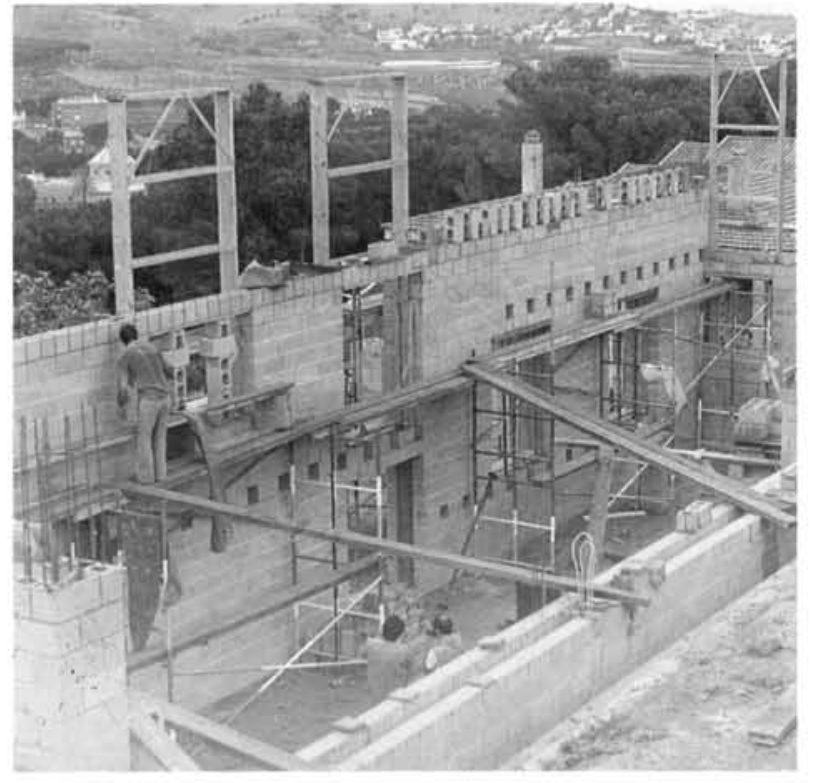

Fig. 6.-Construcción de la caja envolvente.
La construcción de la caja envolvente se realiza independientemente de los forjados (Fig. 5). Requiere doble andamio (interior y exterior) debido a la altura total $(8,40 \mathrm{~m})$ y a la necesidad de acceder desde la cara vista para rejuntar y controlar la planeidad (Fig. 6).

Sobre los muros se construye la cubierta (Fig. 7) que tiene dos capas. La superior, impermeable, es de viguetas pretensadas, bovedillas de hormigón, capa de compresión armada, pendientes, membrana impermeable y grava de acabado y protección (Fig. 8). Se apoya sobre la pared exterior anclada con las armaduras de espera de jambas y esquinas. La capa inferior, aislante, es de viguetas de madera, machihembrado del mismo material y aislamiento adherido sobre la capa superior. Se apoya sobre la pared interior. Ambas capas están separadas por una cámara de aire de $20 \mathrm{~cm}$ que empalma con la del cerramiento vertical (Figs. 9, 10).

La carpinteria exterior es corredera de aluminio sobre premarcos de madera. Los premarcos han sido colocados al levantar el muro exterior. Sirven de cierre para la cámara de aire y escupen las aguas hacia el exterior (Figs. 11, 12).

Los marcos se colocan después de la capa exterior de la cubierta aprovechando los andamios interiores (Fig. 13), de manera que el resto de los trabajos (forjados, cubierta interior, particiones, escaleras, instalaciones y acabados) se realizarán totalmente protegidos del am. biente exterior.

Los huecos acaban debajo de los zunchos, que de este modo se usan también como dinteles, y pueden prolongarse hasta el pavimento para permitir las vistas por 
la parte inferior. Los elementos que abarcan más de una altura pasan sin interrupción por delante del forjado. En este punto no se coloca cristal, sino aislamiento equivalente al de la pared.

El cerramiento se completa con postigos correderos en la cara interior, que suministran oscuridad y aislamiento. Pueden blindarse con chapa metálica en los huecos más vulnerables de los niveles inferiores. Algunas ventanas destinadas principalmente a iluminar y ventilar se completan con reja metálica enrasada con el plano exterior (Fig. 14).

Los forjados son de madera y se apoyan sobre la hoja interior del muro. Son plataformas de viguetas y machihembrado doble cruzado con interposición de absorbente acústico. Las viguetas se introducen en hornacinas de $20 \times 20 \times 20 \mathrm{~cm}$ dispuestas cada $60 \mathrm{~cm}$ en la pared interior (Fig. 15).

Los tabiques son paneles de madera fijos. Coinciden con las viguetas o requieren un suplemento entre viguetas para completar el hermetismo del espacio in. terior. Las puertas son correderas, cuelgan de las viguetas y van guiadas por la parte inferior (Fig. 16).

Las escaleras son de tablas, sin contrahuellas, con zancas apoyadas sobre los bordes de las plataformas que delimitan el hueco central (Fig. 17).

Las instalaciones van adosadas a los muros mediante abrazaderas, con lo que se independizan totalmente de la albañileria. Los recorridos horizontales se efectúan por debajo de los niveles inferiores, desde los que se accede a los puntos de suministro en vertical. Los desagües pasan directamente al exterior (Fig. 14). Por ello las interferencias con el espacio interior son mínimas.

El cableado de la electricidad consta de dos líneas horizontales: una por debajo de los niveles inferiores y otra por la parte superior. Los recorridos secundarios aprovechan el espacio sobrante que queda entre las particiones y las puertas, con derivaciones verticales hacia los puntos de alimentación.

Las instalaciones van adosadas a los muros mediante zas, los conductos enmascarados y las interferencias entre industriales, pero requieren operarios-artesanos y soluciones especiales en giros, empalmes y cambios de sección.

Para el acabado de paramentos verticales, suelos y techos no se aplican pinturas ni revestimientos. Solamente se utilizan alfombras superpuestas de goma y aplacados plásticos en locales húmedos, que están situados sobre el mismo lado del edificio, con objeto de simplificar los trazados de las instalaciones y liberar la fachada principal.

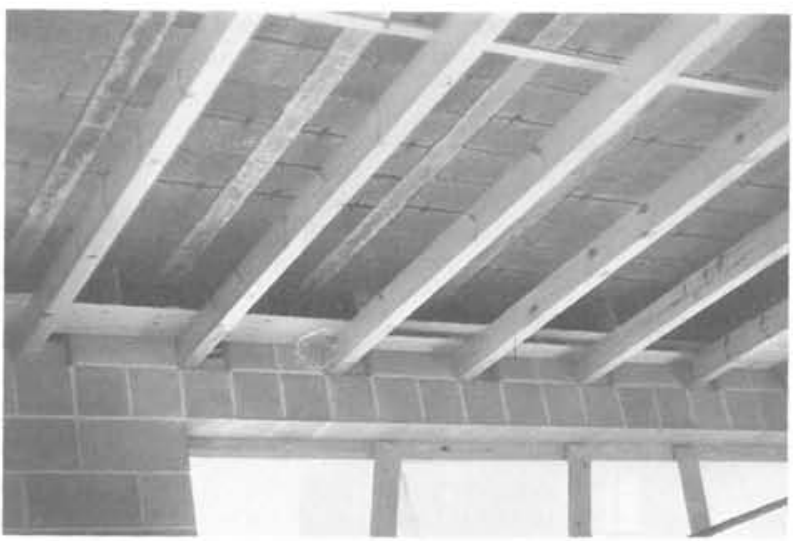

Fig. 9.-Construcción de la capa inferior de la cubierta.

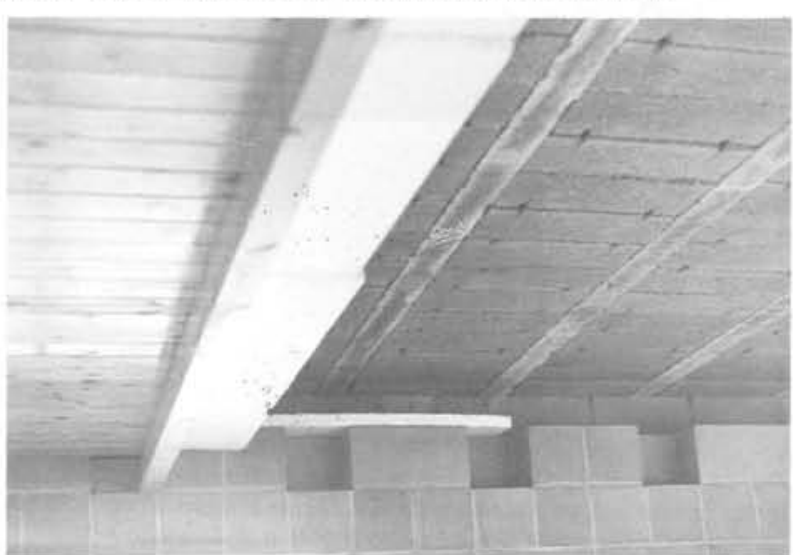

Fig. 10.-Las dos capas de la cubierta durante la construcción de la capa inferior.

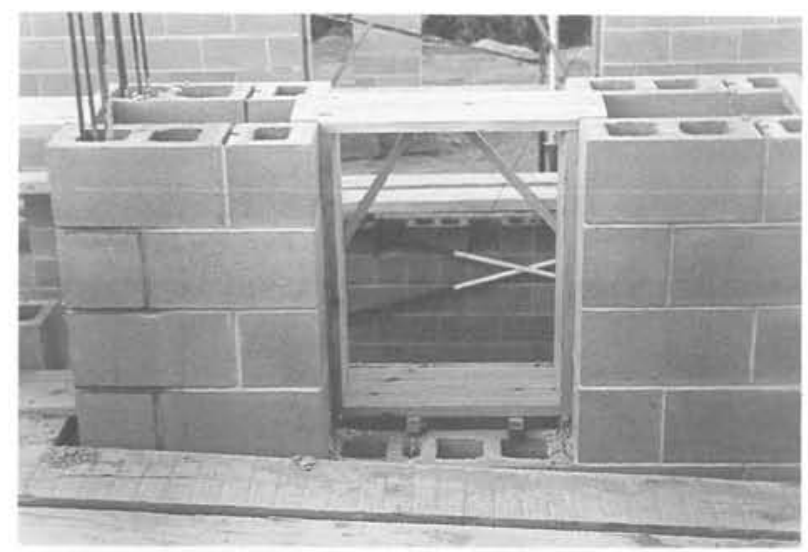

Fig. 11.-El premarco sirve de cierre para la cámara de aire.

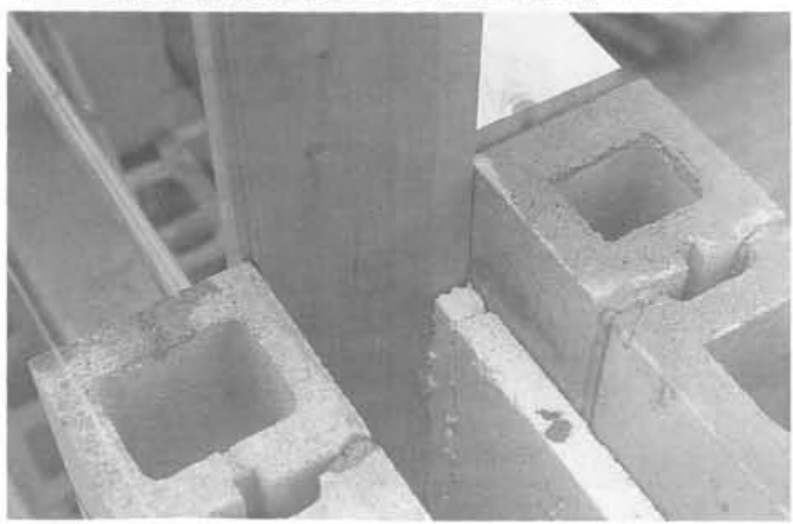

Fig. 12.-Detalle del premarco. El aislamiento va adosado sobre la cara externa de la hoja interior. 


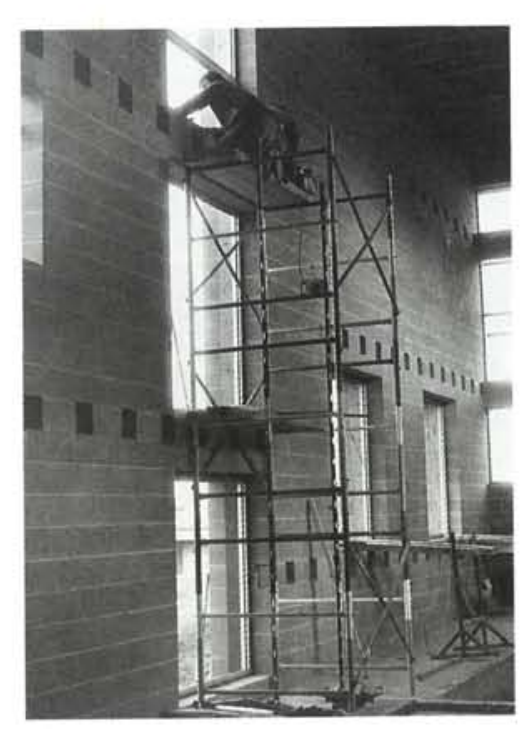

Fig. 14. - Fachada posterior. Las rejas van enrasadas con el plano ex. terior. Los desagües pasan vistos sin afectar al muro. El edificio que. da separado del suelo por un patio inglés cubierto con reja. interior.
Fig. 13.-Colocación de marcos desde el
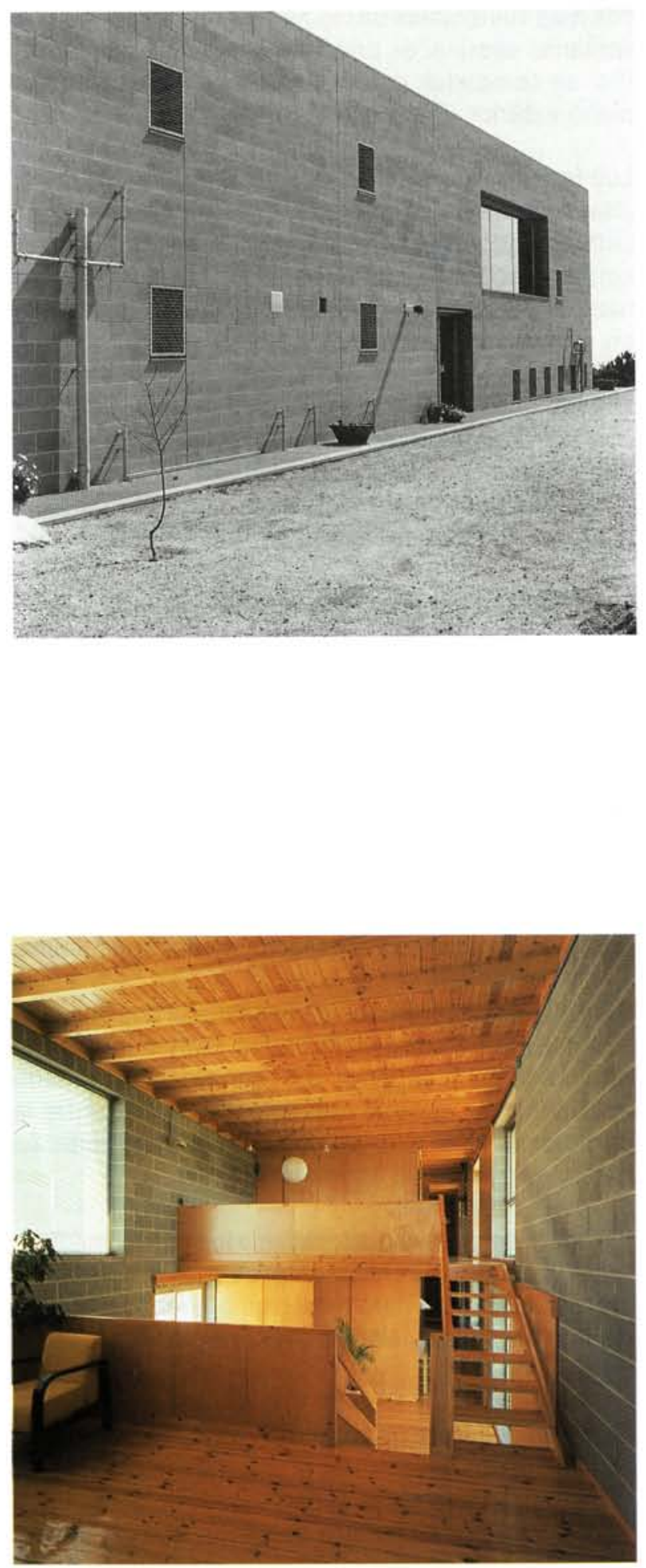

Fig. 17.-Las escaleras son de tablas sobre zancas sin contrahuella, con objeto de no interrumpir la comunicación visual.

http://informesdelaconstruccion.revistas.csic.es 


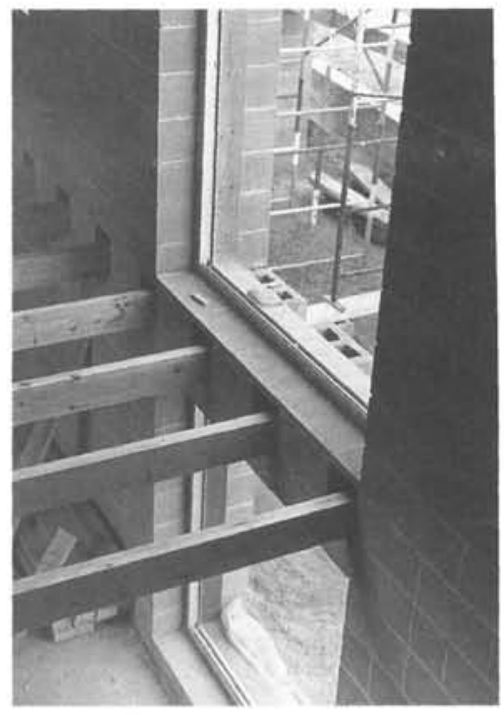

Fig. 15.-Viguetas de madera apoyadas so bre hornacinas de $20 \times 20 \times 20 \mathrm{~cm}$ dis. puestas cada $60 \mathrm{~cm}$ en la pared interior.

\section{ELEMENTOS CONSTRUCTIVOS INDEPENDIENTES}

El sistema utilizado trata por separado los elementos constructivos, con lo que cada uno de ellos puede ser optimizado y tratado independientemente de los demás.

Todas las partidas pueden ser ejecutadas por especialistas diferentes. No es necesario que los industriales coincidan en obra y pueden suprimirse las ayudas de albañileria. Por ello se simplifican extraordinariamente los problemas de coordinación. Los presupuestos parciales pueden pedirse por separado, la ejecución se organiza por fases sucesivas e independientes, las responsabilidades quedan perfectamente delimitadas y se facilitan la dirección y el control.

Este tratamiento diferenciado no produce un abaratamiento sustancial, pero conduce a un aumento considerable de la calidad, simplifica extraordinariamente el mantenimiento de los elementos constructivos y las instalaciones, admite modificaciones posteriores con facilidad y abre una puerta a la autoconstrucción parcial o total.

\section{COMPORTAMIENTO HIGROTÉRMICO}

El comportamiento higrotérmico se caracteriza por la duplicidad de la envolvente que permite impermeabilizar y aislar de manera continua fachadas y cubierta y suprimir totalmente los puentes térmicos.

Los huecos se proyectan de manera que el agua que atraviesa la hoja exterior sea expulsada de nuevo. Para ello se drena la parte inferior de la cámara de aire ver- tical y la cara superior de los dinteles, que podria recoger el goteo procedente de la parte superior.

La cámara y el aislamiento envuelven todo el volumen de manera continua con la única excepción de la carpintería (de madera o aluminio con cámara) y el cristal (que puede ser doble). El aislamiento del hueco puede llegar a ser parecido al del macizo utilizando los postigos.

Se han suprimido todos los puentes térmicos de la construcción convencional. Los forjados se apoyan sobre el muro interior, por lo que no interrumpen el aislamiento ni la cámara. La cubierta es doble para evitar que el último forjado tenga que salir al exterior. De este modo tampoco se producen interrupciones del aislamiento y la cámara, y se individualiza la capa impermeable (exterior) de la aislante (interior), del mismo modo que se ha hecho con el cerramiento vertical. Las jambas se resuelven con premarcos de madera, los dinteles se doblan a la altura de cada zuncho y las esquinas se conectan solamente con los estribos galvanizados de refuerzo del pilar embebido interior (Figs. 18, 19).

Como la orientación con vistas es al noroeste, se ha proyectado una ventana de grandes dimensiones en la fachada opuesta para obtener el asoleamiento del espacio interior (Fig. 20).

El resultado de invierno es muy favorable porque se obtiene una masa caliente interior muy bien aislada. $4.000 \mathrm{kp}$ de leña mezclada de pino, roble y encina bastan cada invierno para mantener constantemente a $21{ }^{\circ} \mathrm{C}$ los $676 \mathrm{~m}^{3}$ de volumen interior.

En verano se puede mantener el edificio aislado ventilando la cámara de aire. De este modo se evita que la temperatura pase al interior. 

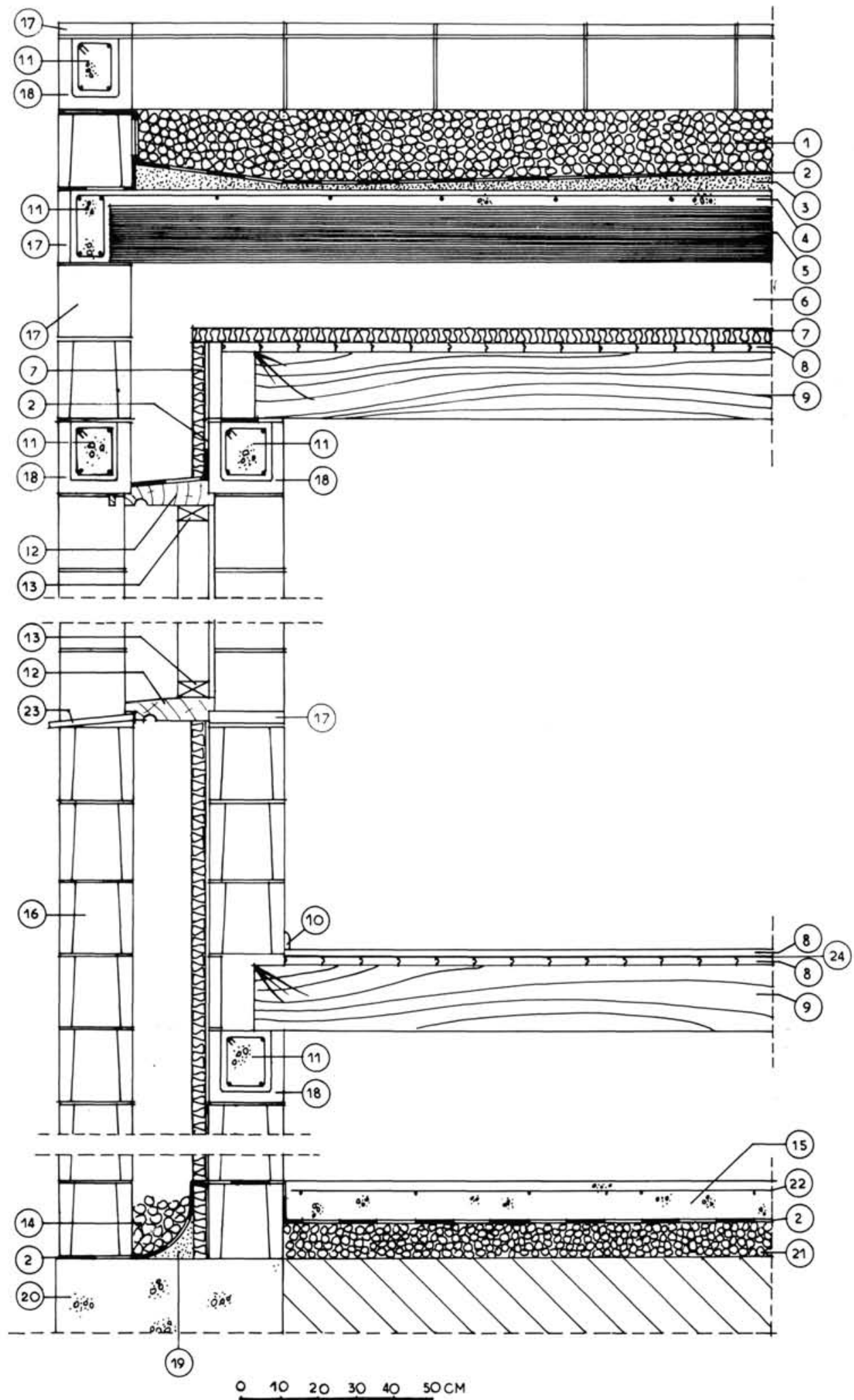

Fig. 18.-Detalle sección: 1. Grava.-2. Membrana impermeable.-3. Hormigón ligero para formación de pendientes.-4. Hormigón armado.-5. Vigueta pretensada.-6. Cámara de aire.-7. Aislamiento.8. Machihembrado de madera.-9. Vigueta de madera.-10. Zócalo de madera.-11. Zuncho.-12. Pre marco-13. Marco.-14. Drenaje-15. Hormigón.16. Bloque hueco-17. Pieza maciza.-18. Pieza en U para zunchos.-19. Mortero hidrofugado.-20. Cimiento.-21. Encachado.-22. Armadura.-23. Vierteaguas de piedra.-24. Absorbente acústico. 


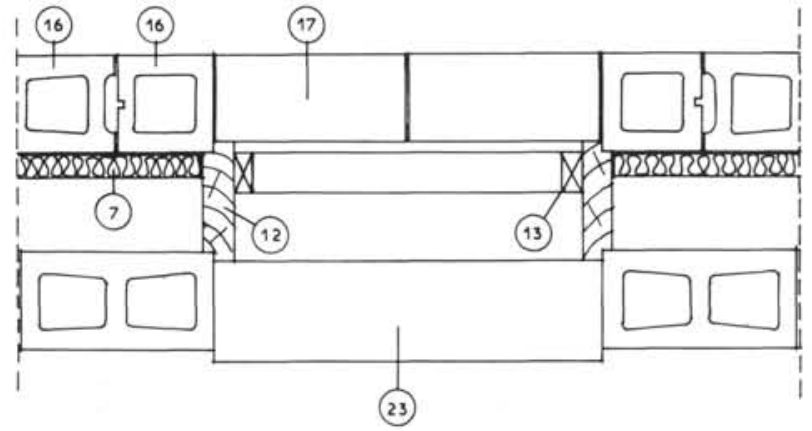

Fig. 19.-Detalle planta: 7. Aislamiento.-12. Premarco.-13. Marco.16. Bloque hueco de mortero.-17. Pieza maciza de mortero. 23. Vierteaguas.

\section{EL AMBIENTE INTERIOR}

El ambiente interior queda definido por la forma, las dimensiones, la luz, los colores, la textura de los materiales y otros aspectos tales como el sonido, el olor, las plantas y la ocupación.

La sencillez del contenedor envolvente no limita la calidad del espacio interior. La vivienda se desarrolla en

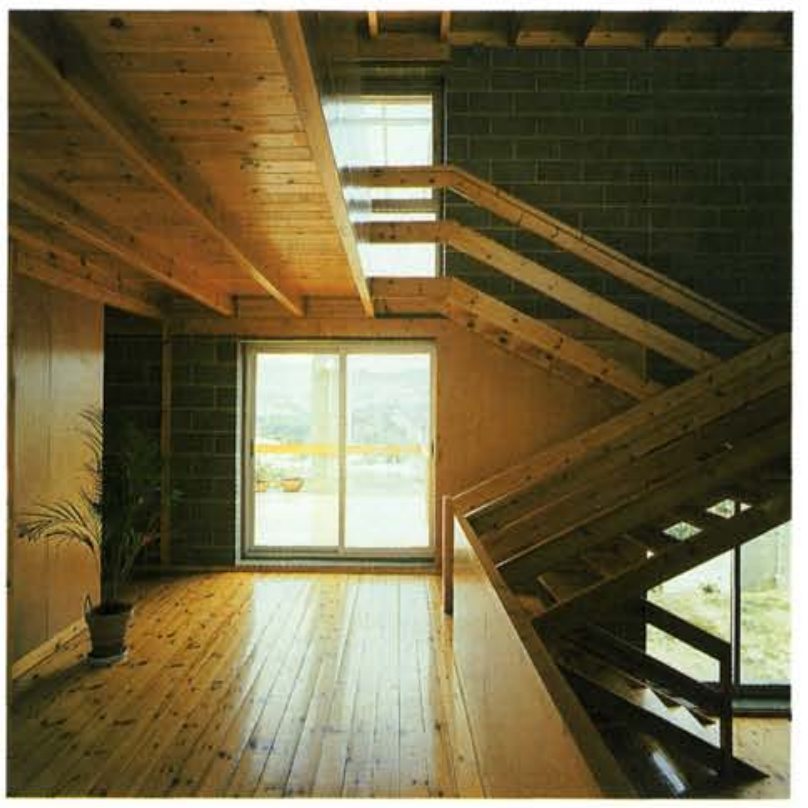

Fig. 21.-El espacio central tiene la misma altura que el contenedor. Bien iluminado $y$ ventilado, conecta las plataformas entre si.

(C) Consejo Superior de Investigaciones Científicas Licencia Creative Commons 3.0 España (by-nc)

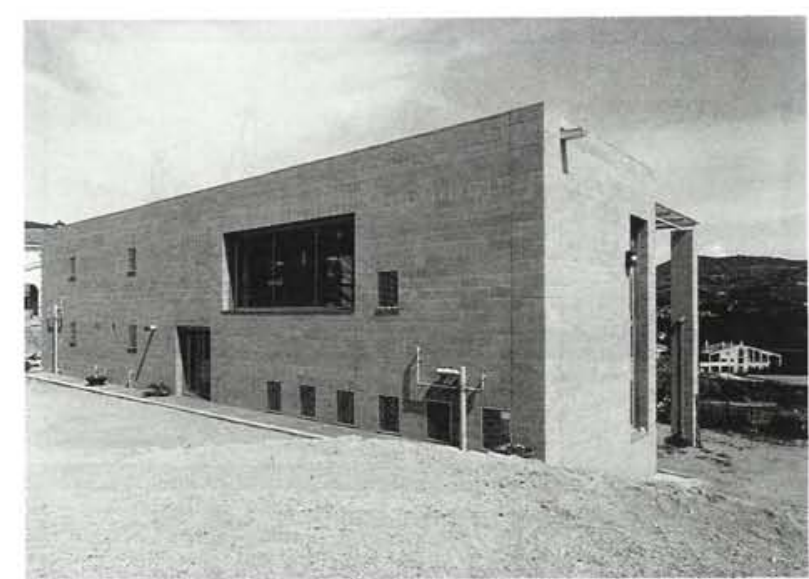

Fig. 20.-Fachada suroeste. Una ventana de grandes dimensiones permite el asoleamiento del espacio interior.

cuatro plataformas a distinto nivel. El espacio central, bien iluminado y ventilado, las conecta entre si (Fig. 21). Tiene la misma altura que el contenedor y se configura como el ámbito de acceso, relación, comunicación vertical y de identificación del interior, contiguo a los subespacios de las plataformas, más privados y de altura muy inferior. No tiene una forma geométrica definida y tiende a fluir entre las diferentes partes de la vivienda, prolongándose hacia los extremos y unificando el núcleo interior (Fig. 22).

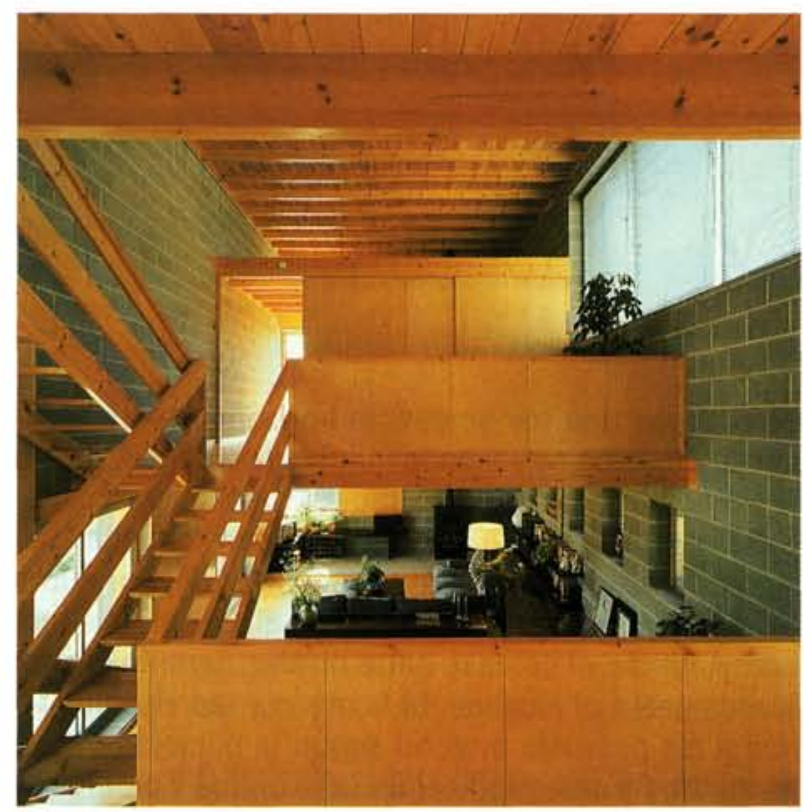

Fig. 22.-Detalle del espacio central. Al tondo el nivel 3. Abajo el nivel 1 .

http://informesdelaconstruccion.revistas.csic.es 

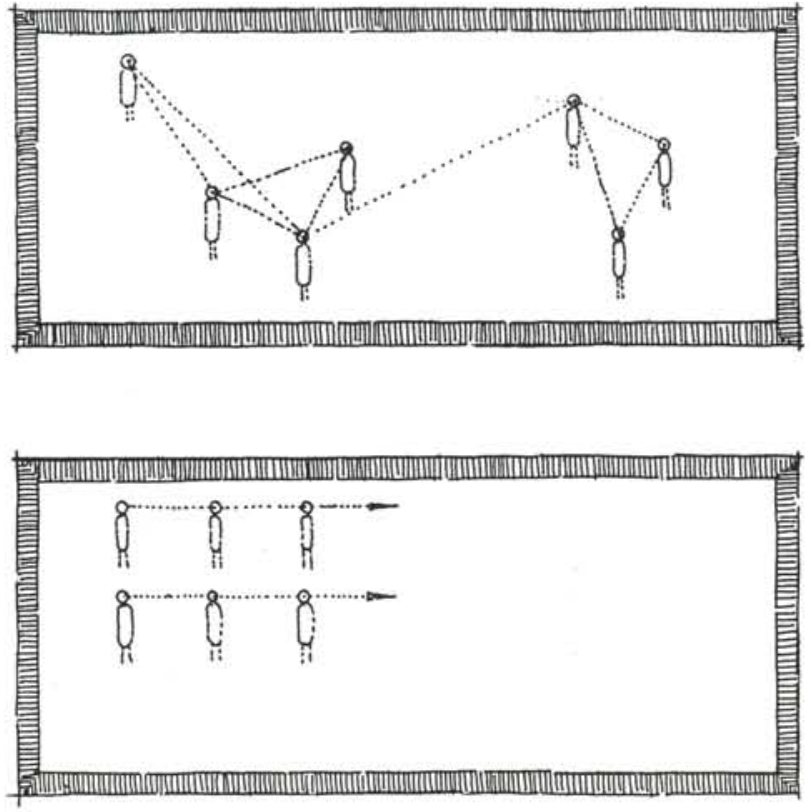

Fig. 23.-El desfase entre plataformas permite al usuario ocupar y percibir todos los espacios. No queda limitado a dos franjas horizonta. les separadas, sin conexión.

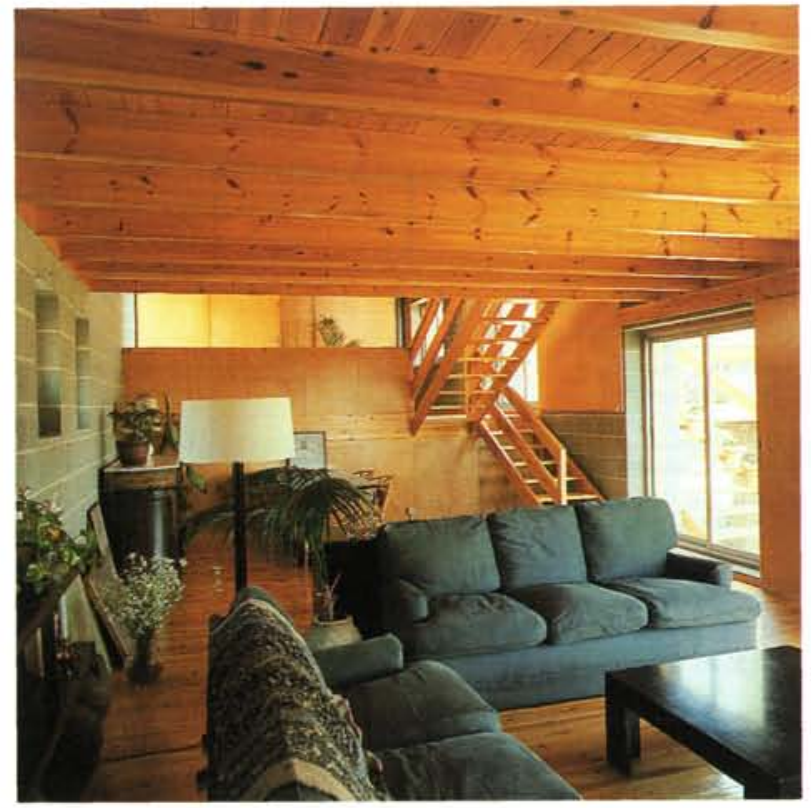

Fig. 24. - El ambiente interior del nivel 1 (sala de estar) conecta visual. mente con el del nivel 2 (acceso).
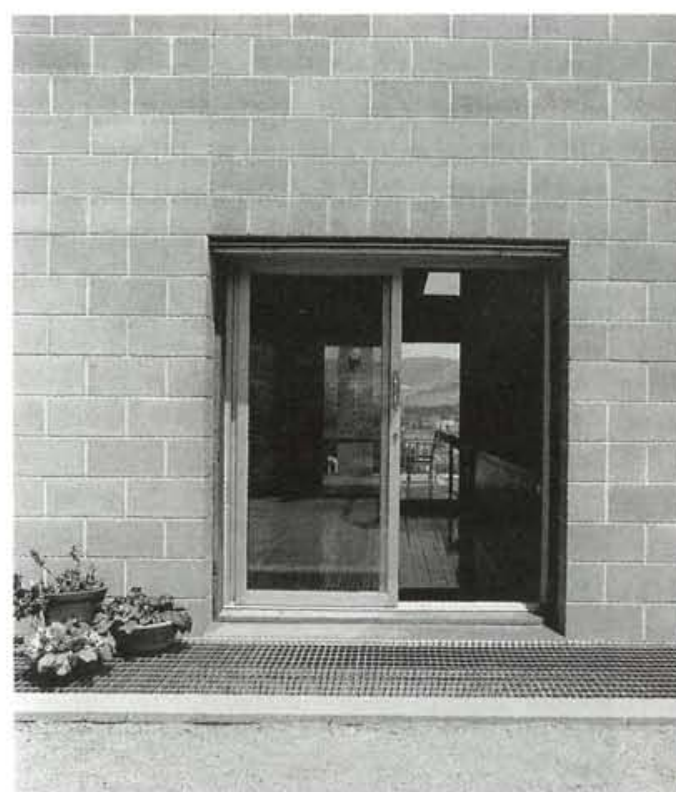

Se produce una transparencia horizontal entre plataformas, más bajas y menos iluminadas, a través de este espacio vertical de gran altura y mucha iluminación y las escaleras, que carecen de contrahuella para aumentar la comunicación visual (Fig. 16). Por ello la percepción del espacio interior es diferente a la habitual. Además, el desfase entre niveles permite que los suelos estén al alcance de la mano y las visuales co. rran a ras de suelo o techo según la posición del espectador. De este modo el usuario ocupa y percibe todos los espacios. No se limita a dos franjas horizontales y separadas sin conexión (Figs. 23, 24).
Fig. 25.-Transparencia transversal del edificio propiciada por su reducido espesor.

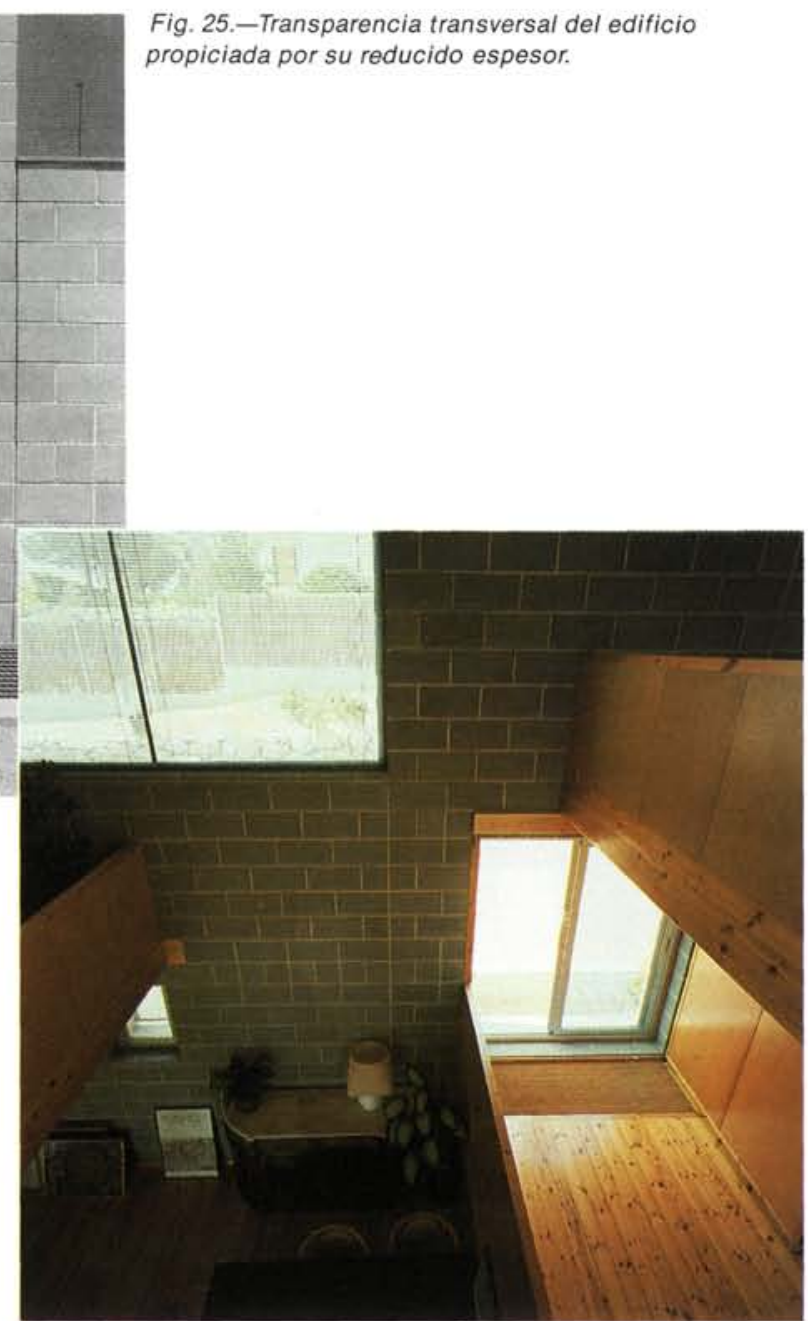

Fig. 26. - El acabado interior combina el bloque de mortero gris con la madera. 


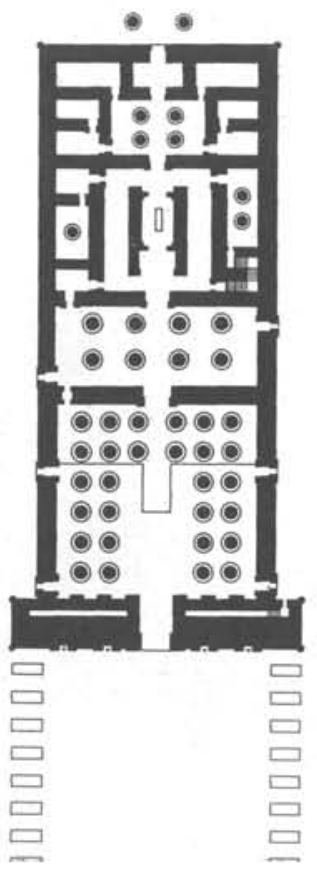

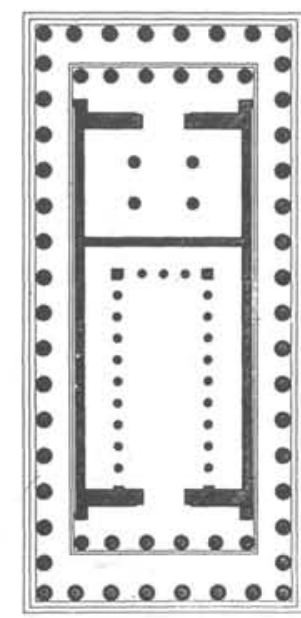

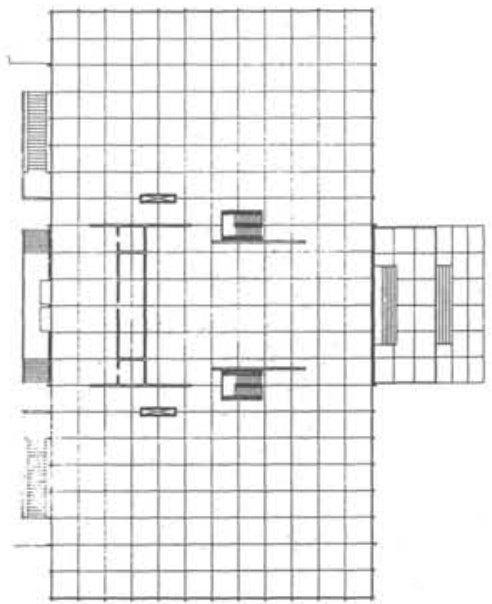

Fig. 27.-Algunos ejemplos de la participación del espesor del muro en la configuración del espacio arquitectónico. De izquierda a derecha: Templo de Khons (Luxor, 1198-1168 a.C.); Partenón (Acrópolis de Atenas, $447-432$ a.C.); Crown Hall (Chicago, 1955).

La facilidad de comunicación visual se refuerza con la transparencia transversal del edificio propiciada por su reducido espesor (Fig. 25).

El aspecto interior combina el bloque visto de mortero gris de las paredes con la madera de suelos, techos, tabiques, puertas, armarios y postigos (Fig. 26). Pueden considerarse dos partes claramente diferenciadas. En las piezas menores predomina la madera, que es un material cálido, y presentan un solo lienzo de hormigón. En cambio, el espacio principal, que no está compartimentado, muestra una superficie de fábrica mayor. El usuario puede controlar el aspecto colocando estanterías, tapices, cuadros, carteles o vegetación interior.

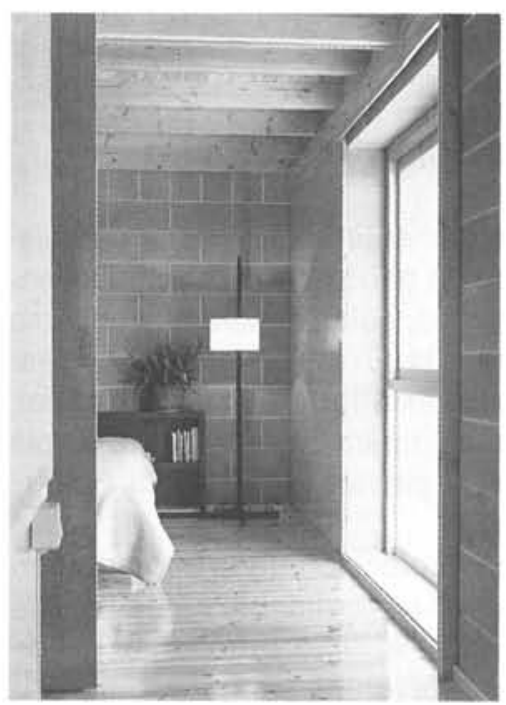

(c) Consejo Superior de Investigaciones Científicas Licencia Creative Commons 3.0 España (by-nc)
Los $60 \mathrm{~cm}$ de espesor recuperan una dimensión de la arquitectura (Fig. 27) que proporciona volumen al cerramiento exterior, determina un espacio de transición al penetrar en el edificio y permite la colocación de cerramientos complejos compuestos por capas diferenciadas tales como cortinas, postigos, cristales, mosquiteras, persianas y rejas, sin necesidad de sobresalir.

\section{FACILIDAD DE ADAPTACIÓN AL USUARIO}

El sistema constructivo adoptado permite hacer modificaciones con facilidad, sin obra, albañiles ni demo. liciones, para adaptar la distribución al programa cambiante del usuario durante el transcurso de su vida. Se puede cambiar no solamente el recorrido de las instalaciones, sino también la distribución en planta de las particiones, e incluso la disposición de las plataformas que están simplemente apoyadas en seco sobre las hornacinas de la pared.

La organización interior permitiria la segregación de unidades con acceso independiente para acomodar invitados, padres, hijos semiemancipados, hermanos y hermanas solteras, etcétera.

Esta vivienda puede interpretarse como un prototipo adaptable a otros emplazamientos. Serian posibles variaciones en el tipo de cubierta, que podría ser inclinada. Modificando la altura de la cámara podría albergar un almacén doméstico para el depósito de agua, muebles, trastos viejos, alimentos, provisiones, leña, car- 
bón o para criar aves y conejos. También se podria cambiar la cantidad de aislamiento y el tratamiento de los huecos para responder a condiciones diversas del clima local e incluso plantear otro sistema compositivo de las fachadas para adecuarlas al ambiente exterior.

La calidad de los elementos constructivos podría adaptarse a la economía del usuario utilizando otras maderas en el suelo, las particiones y la carpintería, otros revestimientos de locales húmedos, utilizando doble cristal o ventana, modificando la griferia, los sanitarios y los armarios de cocina, etcétera.

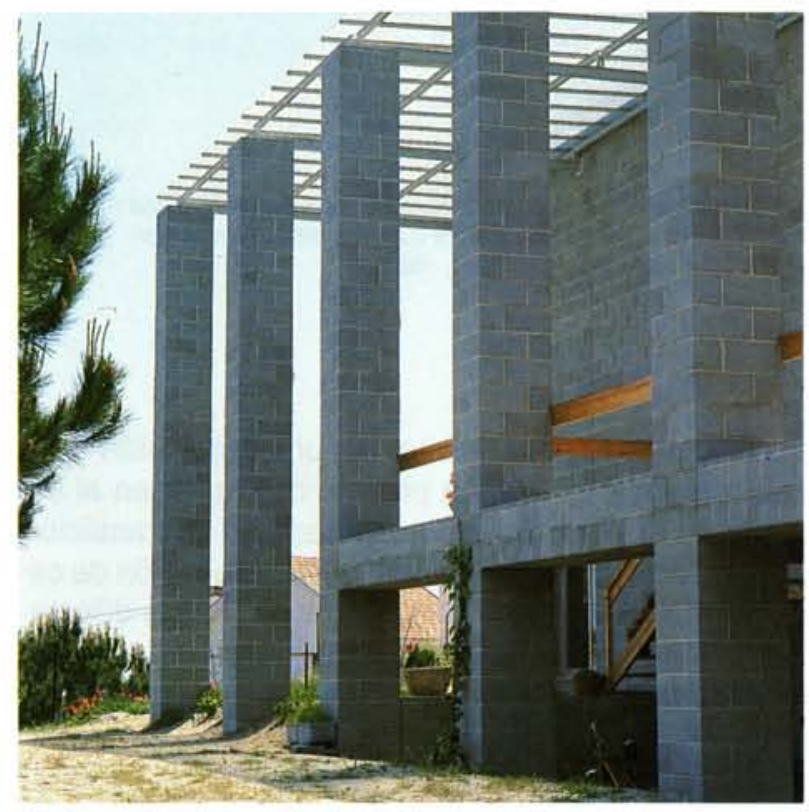

Fig. 28.-El porche crea un espacio de transición y protege la fachada.

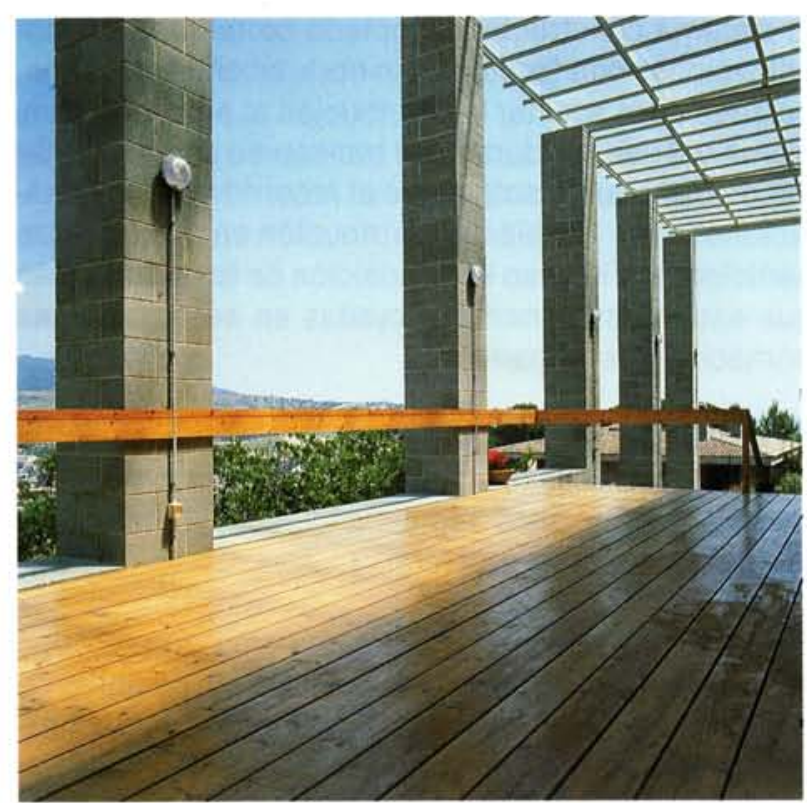

Fig. 29.-Prolongación hacia la terraza del espacio interior.

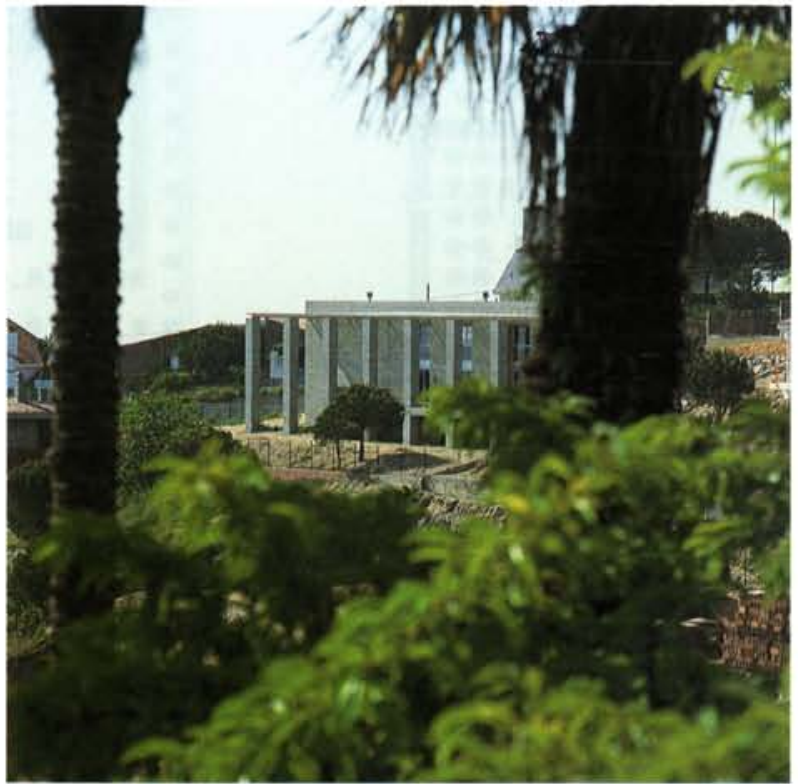

Fig. 30.-El pórtico de la terraza filtra la volumetria del paralelepipedo.

\section{FACILIDAD DE ADAPTACIÓN AL ENTORNO}

Para adaptar el edificio al entorno, se puede completar el rectángulo base con otros espacios complementarios tales como porches, galerías, toldos y terrazas de protección para el sol, la lluvia y el viento, para crear un filtro entre el espacio exterior y el espacio interior, para enmarcar las vistas o para suavizar la presencia del paralelepípedo en el paisaje (Figs. 28, 29, 30).

La grava de acabado y protección de la cubierta permite que se perciba como un pavimento natural desde cotas superiores a las del edificio, evitando el desorden de los planos de pendientes sin tratar. 


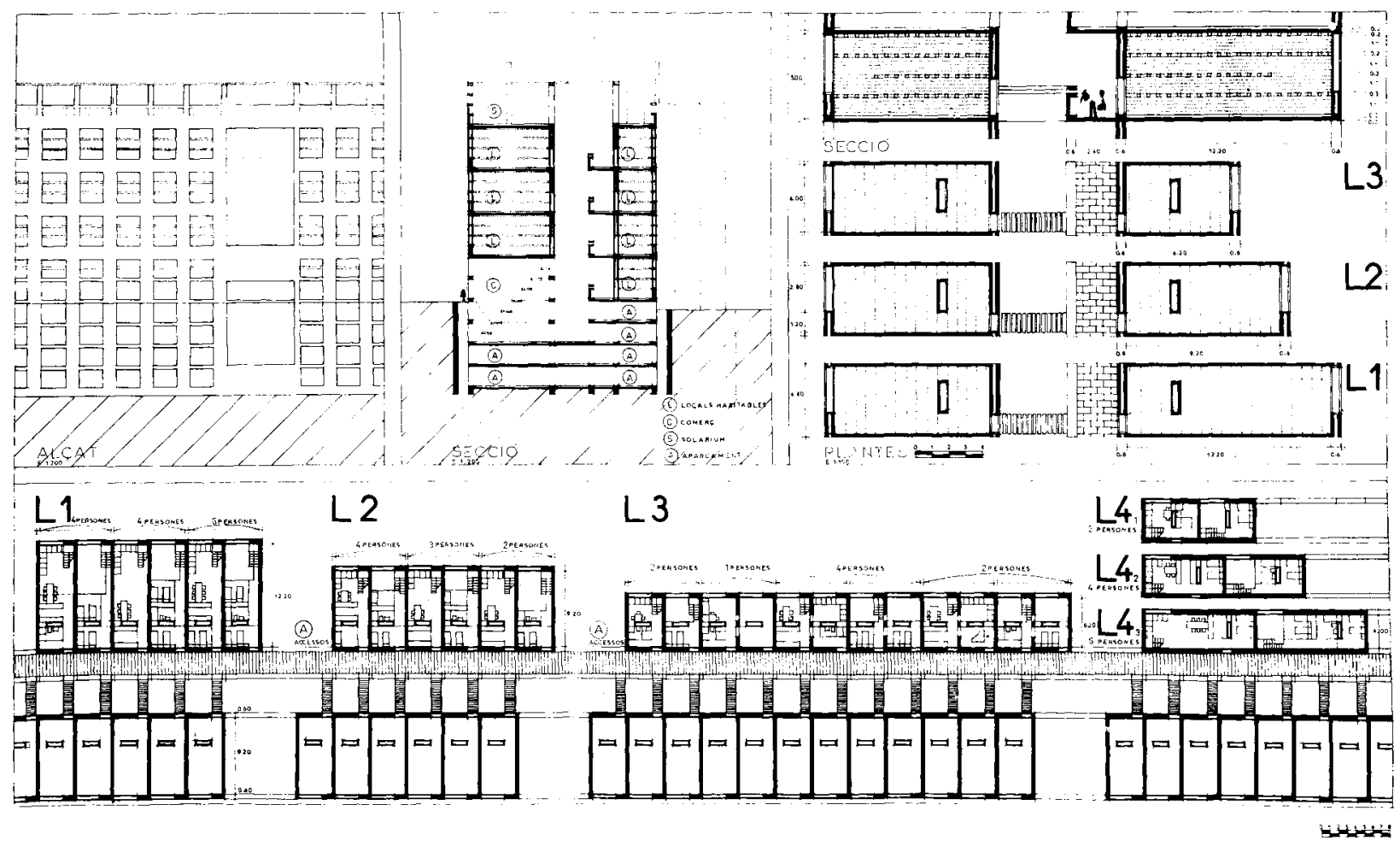

Fig. 31.-Propuesta de bloque de locales habitables.

\section{DE LA CASA RIERA DE ALELLA A LOS LOCALES HABITABLES}

El resultado de esta experiencia permite formular una propuesta a escala urbana. Se trata de un bloque contenedor de locales habitables (Fig. 31). Cada local es una caja delimitada por forjados de hormigón y paredes armadas de bloque de mortero gris. Mide $4 \mathrm{~m}$ de anchura interior, $5 \mathrm{~m}$ de altura y 12,20 m (tipo L1), 9,20 m (tipo L2) ó 6,20 m (tipo L3) de profundidad.

Suelos y techos van acabados con machihembrado de madera sobre viguetas, ligeramente separado del forjado de hormigón para alojar una cámara aislada y los conductos de las instalaciones que se enchufan en el patinejo interior.

Los accesos se realizan en vertical a través de escaleras y montacargas y en horizontal mediante amplias galerías a modo de calles.

Cada usuario dispondría de los módulos que necesitara o pudiese, compartimentándolos de acuerdo con su forma de vida y sus posibilidades económicas. Apar- te de las distribuciones convencionales (Fig. 31), serían posibles otros tipos de agrupación, puesto que los locales pueden comunicarse a través de una abertura de $1,80 \times 2,20 \mathrm{~m}$ practicada en la pared transversal:

- Con tres módulos seguidos podría organizarse un estudio compartido en el centro comunicado con una vivienda o local privado a cada lado, accesibles también con independencia desde el exterior.

- Otros usos posibles como los de taller de pintura o reparaciones, restaurante, bar, granja o comercio, podrian disponer de los locales que fuesen necesarios, incluso para vivienda o almacén.

La facultad de uso eficaz y polivalente se basa en la posibilidad de acceso independiente a cada local y de adición de locales contiguos para formar agrupaciones. Además, la compartimentación interior horizontal es ligera y se realizaría en seco. Las instalaciones se centralizan en el patinejo interior, con recorridos hacia los puntos de consumo alojados en la cámara del suelo o techo, debajo o encima del machihembrado de madera, es decir, fácilmente registrables para modificarlos o mantenerlos, sin interferencias con la estructura envolvente general. 
El conjunto de habitáculos se configura como un edificio urbano adaptable a diferentes tipos de parcelación mediante la combinación de profundidades de módulos diferentes y la disposición de las galerias de acceso. Podría colocarse aislado o entre medianeras en zonas ya consolidadas, remodeladas o de nueva creación.

\section{CONCLUSIONES}

La Casa Riera de Alella es una vivienda experimental basada en la construcción de un contenedor rectangular doble de bloque de mortero y la independiencia entre los elementos constructivos. Ha constatado la viabilidad de utilizar un sistema diferente con objeto de conseguir la adecuación al entorno y las condiciones climáticas del lugar, la adaptación al programa y la economía del usuario a lo largo del tiempo y la calidad ambiental del espacio interior.

El sistema constructivo se ha planteado con claridad y sencillez, evita la intervención simultánea en obra de especialistas diferentes, facilita las operaciones de mantenimiento y modificación y admitiria la posibili- dad de recurrir a la autoconstrucción. El comportamiento higrotérmico se ha optimizado utilizando el doble contenedor con aislamiento y ventilación.

En base a esta experiencia puede formularse una propuesta de construcción de locales habitables aplicando los mismos principios a escala superior.

\section{BIBLIOGRAFIA}

J. Alonso: "La construcción con bloque: orientaciones cons. tructivas y de proyecto" Informes de la Construcción, N. ${ }^{\circ} 326$, Dic. 1980, págs. 29 a 49 .

D. Bernstein, J. P. Champetier \& F. Peiffer: "Nuevas técnicas en la obra de fábrica. El muro de dos hojas en la arquitectura de hoy". G. Gili, Barcelona, 1985.

M. Gage \& T. Kirkbride: "Design in blockwork". The Architectural Press, Londres, 1980.

J. Llorens \& A. Soldevila: "Viviendas económicas realizadas con bloques de hormigón. Experiencias y prototipos". Infor. mes de la Construcción, N. ${ }^{\circ}$ 344-345, Oct.-Nov. 1982, págs. 35 a 43 .

\section{publicación del ICCET/CSIC}

\section{INSPECCION DE OBRAS DAÑADAS POR CORROSION DE ARMADURAS}

El presente Manual va dirigido principalmente a técnicos especializados y laboratorios que tienen que intervenir en el dictamen de la situación de deterioro de estructuras de hormigón armado dañadas por corrosión de armaduras.

Comienza con un resumen recordatorio de los factores principales a los que se pueden deber los daños prematuros por corrosión de armaduras, para seguir con algunas índicaciones de cómo se deben realizar las inspecciones, y de los ensayos y la metodología que se recomienda realizar para poder dictaminar con precisión las causas de daño.

A continuación se hacen una serie de comentarios sobre la vida residual de estructuras dañadas, sobre el riesgo de corrosión futura, el seguimiento necesario de una estructura reparada y una breve enumeración de métodos de reparación y consideraciones básicas a tener en cuenta en la recomendación de un determinado método. Se aporta una breve relación bibliográfica.

Finalmente se incluyen en forma de ficha la descripción de algunos casos de corrosión de armaduras detectados en nuestro país.

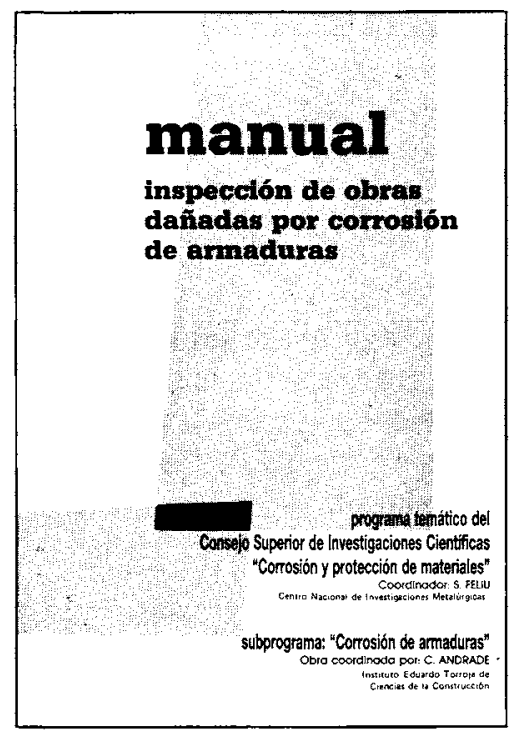

